\title{
Earplug Actuator Selection for a Miniature Personal Active Hearing Protection System
}

\author{
Marek PAWEŁCZYK, Mariusz LATOS \\ Silesian University of Technology \\ Institute of Automatic Control \\ Akademicka 16, 44-100 Gliwice, Poland \\ e-mail: \{Marek.Pawelczyk; Mariusz.Latos\}@polsl.pl \\ (received April 26, 2010; accepted May 14, 2010)
}

\begin{abstract}
There are many industrial environments which are exposed to a high-level noise. It is necessary to protect people from the noise. Most of the time, the consumer requires a miniature version of a noise canceller to satisfy the internal working place requirements. Very important thing is to select the most appropriate personal hearing protection device, for example an earplug. It should guarantee high passive noise attenuation and allow for secondary sound generation in case of active control. In many cases the noise is nonstationary. For instance, some of the noisy devices are switched on and off, speed of some rotors or fans changes, etc. To avoid any severe transient acoustic effects due to potential convergence problems of adaptive systems, a fixed-parameter approach to control is appreciated. If the noise were stationary, it would be possible to design an optimal control filter minimising variance of the signal being the effect of the acoustic noise and the secondary sound interference. Because of noise nonstationarity for most applications, the idea of generalised disturbance defined by a frequency window of different types has been developed by the authors and announced in previous publications. The aim of this paper is to apply such an approach to different earplugs and verify its noise reduction properties. Simulation experiments are conducted based on real world measurements performed using the G.R.A.S. artificial head equipped with an artificial mechanical ear, and the noise recorded in a power plant.
\end{abstract}

Keywords: active noise control, fixed-parameter control, high-level noise, nonstationary noise, feedforward control, earplug, hearing protection.

\section{Introduction}

The research reported in this paper is a part of a larger project, which aims at designing a miniature personal active hearing protector supporting verbal communication among a group of users (LATOS, PAWEŁCZYK, 2009a, 2009b, 2009c). The properties of the hearing protection device have great influence on the overall noise reduction results. A proper device should ensure high active reduction, 
and exhibit sufficient passive attenuation. The better the passive protection, the lower energy is required for the active system. Research on active hearing protection has a long tradition in Poland (Engel, 1984; Engel, Kowal, 1995; Engel, Makarewicz, 2001; PaWelczyK, 1999). It has also been extensively undertaken worldwide, including recent years (Bockstael, De Greve, 2008; Saxena et al., 2008; Williams, 2008; Elliott, 2009).

It is justified to design a fixed-parameter active control system if only the acousto-electric plant differs marginally when compared to its model and the noise is stationary (LAtos, PAWEŁCZYK, 2009a, 2009b, 2009c; PAWEŁCZYK, 2005, 2009). Such a system is generally free of transient acoustic effects unpleasant to the user, what is an important drawback of an adaptive system (ELLIOTT, 2001; Larsson, et al., 2009; Nelson, Elliott, 1992; Widrow, Stearns, 1985), which might even diverge under some circumstances. On the other hand, the fixed-parameter system does not require sophisticated calculations and is thus simpler in implementation and cheaper than an adaptive system. The problem of nonstationarity of the noise was undertaken by the authors, who proposed the idea of a generalised disturbance and successfully applied it to the feedforward structure (LATos, PAWEŁCZYK, 2009a, 2009b). The Wiener filter design procedure is used for such disturbance. Experiments are performed to compare the performance of the control systems for different earplugs, applied to the G.R.A.S. artificial head.

\section{Control system}

The general feedforward architecture is presented in Fig. 1, where $y(n)$ is the system output referred to as the error signal at the point of interest in acoustic space, $d(n)$ is the output disturbance to be reduced, $x(n)$ is a reference signal correlated with that disturbance, $P$ is the primary path related to noise propagation between the reference and error signal measurement points, $S$ is the secondary path related to secondary sound propagation between the secondary source and the point of interest, and $W$ is the control filter. $P$ and $S$ include the electronic apparatus required for active noise control.

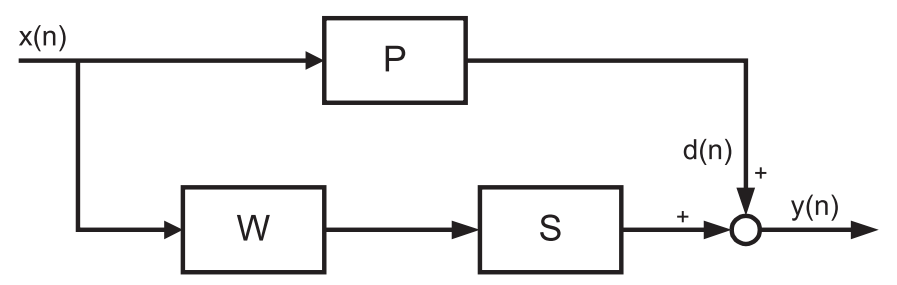

Fig. 1. Feedforward structure.

One of the possible solutions for control, particularly justified for active noise reduction, is to minimise the mean square value of the error signal. 
Then, the sub-optimal causal stable Wiener control filter can be easily found, which in the discrete frequency domain takes the form (LATOS, PAWEŁCZYK, 2009a, 2009b; PAWEeCZyK, 2005; Elliott, 2001)

$$
W_{\mathrm{opt}+}(m)=-\frac{1}{F(m) \hat{S}^{(o)}(m)}\left\{\frac{\hat{P}(m) F(m)}{\hat{S}^{(i)}(m)}\right\}_{+} .
$$

In this equation $m$ is the discrete frequency index, $F(m)$ is the frequency response of a minimum phase filter modelling the reference signal $x(n)$, and the other symbols stand for frequency responses of the primary path model $\hat{P}$, inner, $\hat{S}^{(i)}$ and outer, $\hat{S}^{(o)}$, factors of the secondary path model (VIDYASAGAR, 1985).

The fixed-parameter control filters designed, based on the disturbance model, may be far from the optimal solution if the noise is non-stationary, and noise control results may be poor. However, similar design procedure can be used for the generalised disturbance defined by a window-type PSD for frequencies of interest (Fig. 2). The square root of the PSD may be used as the filter $F(m)$ in (1) (LATOs, PAWEŁCZYK, 2009a, 2009b, 2009c).

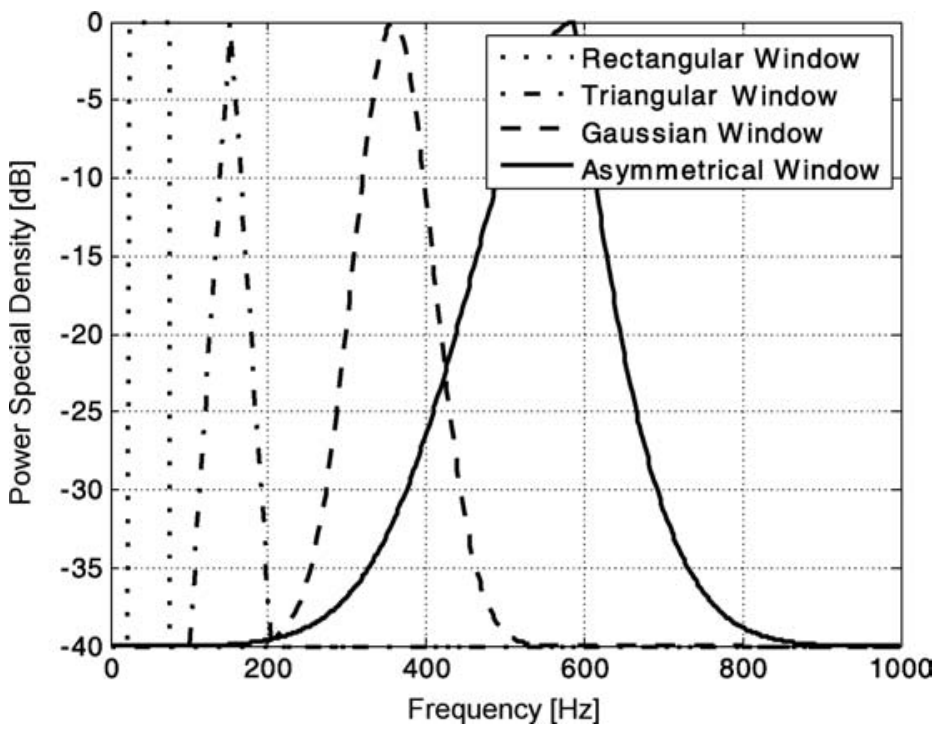

Fig. 2. Window-type magnitude of the generalised disturbance PSD.

Such filter does not bear information about the phase of the disturbance. The phase relation between the reference and error signal, required for the feedforward system, is exhibited by the model of the primary path. For success of the considered control system, the group delay introduced by the secondary path should not be higher than the group delay of the primary path. Assuming that for a small earplug, the distance between the reference microphone mounted outside the earplug and the eardrum is about $3 \mathrm{~cm}$, the sampling frequency higher than $11 \mathrm{kHz}$ should be used. 


\section{System configuration}

Three types of earplugs have been taken into consideration: Creative Zen Aurvana, Sony MDR-NC022 and Sennheiser IE8. Photos of these earplugs are presented in Figs. 3a, 4a, 5a and laboratory set-ups in Figs. 3b, 4b, 5b, respectively. Only the Sony earplug have an internal built-in microphone, working as the reference microphone. In case of Creative and Sennheiser earplugs, an external microphone has to be used. If any of the earplugs is found suitable for active noise control, a small-size microphone will be attached at its back side. To each of the described above earplugs, several rubber earpads are added. For the Creative and Sony earplugs there are two pairs of rubber earpads of different size, and Sennheiser offers nine pairs of different size and material.

a)

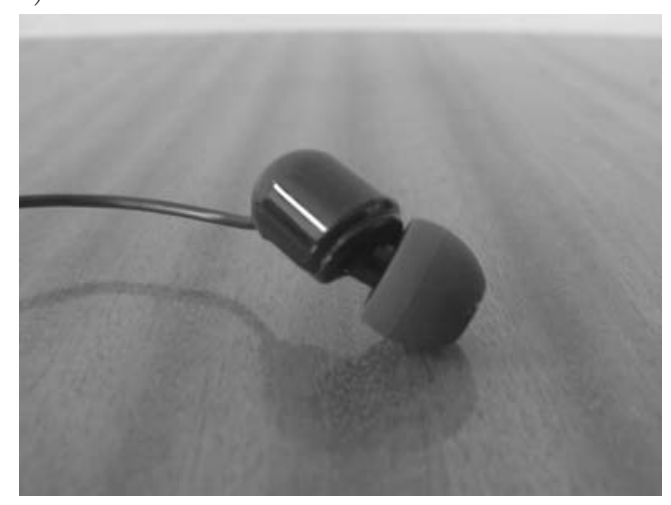

b)

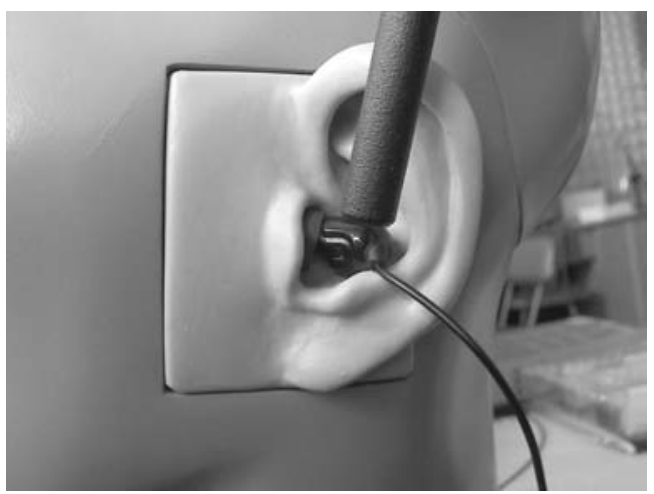

Fig. 3. a) Creative Zen Aurvana earplug; b) A laboratory setup with the Creative earplug sealed to the ear canal of the G.R.A.S. artificial head, and external reference microphone located very close to the earplug.

a)

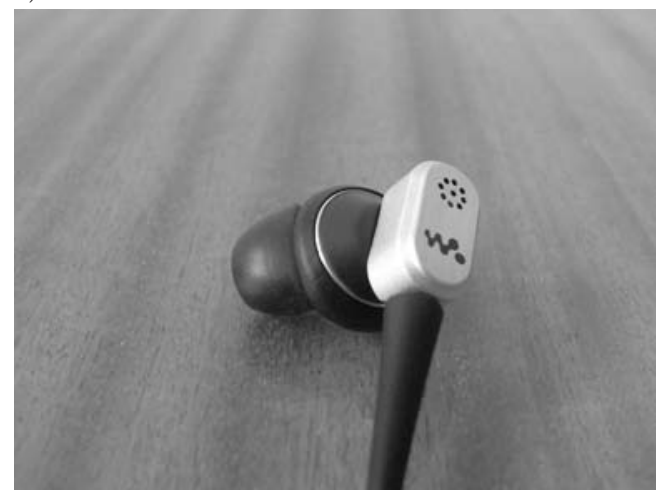

b)

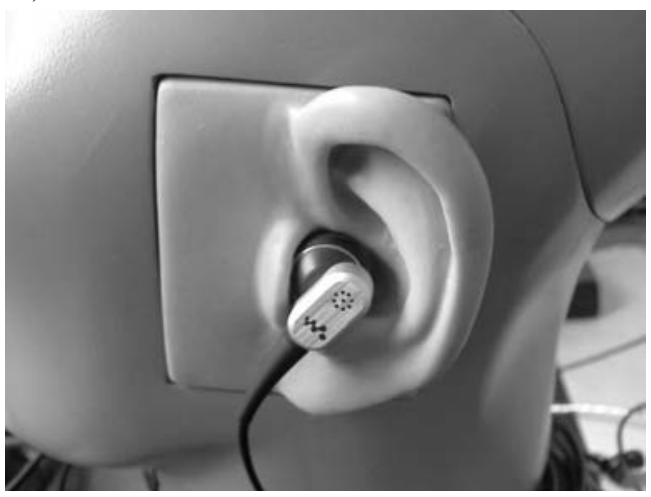

Fig. 4. a) Sony MDR-NC022 earplug with microphone built-in at the back side; b) A laboratory setup with the Sony earplug sealed to the ear canal of the G.R.A.S. artificial head. 
a)

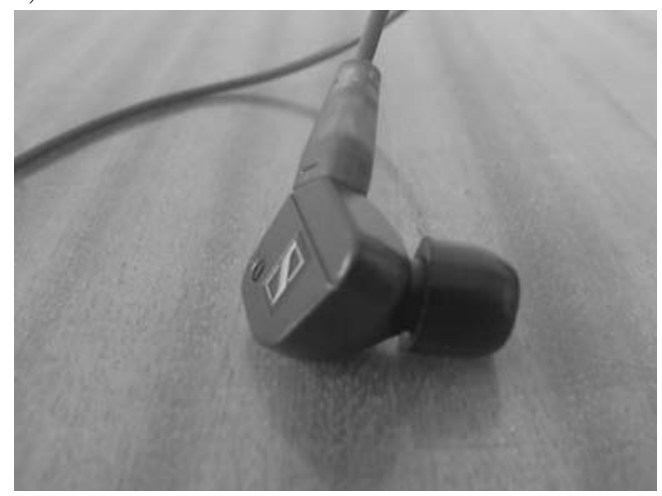

b)

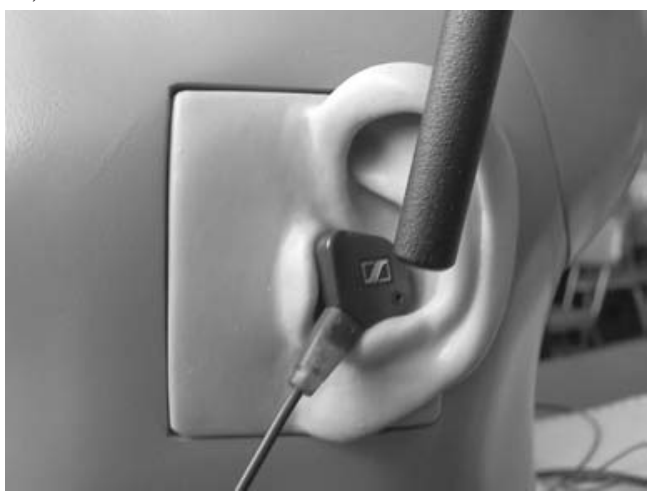

Fig. 5. a) Sennheiser IE8 earplug; b) A laboratory setup with Sennheiser earplug sealed to the ear canal of the G.R.A.S. artificial head, and external reference microphone located very close to the earplug.

Parameters declared by the producers of earplugs are presented in Table 1 .

Table 1. Earplugs parameters declared by producers.

\begin{tabular}{|l|c|c|c|c|c|c|}
\hline & $\begin{array}{c}\text { Impedance } \\
{[\Omega]}\end{array}$ & $\begin{array}{c}\text { Frequency } \\
\text { response } \\
{[\mathrm{Hz}]}\end{array}$ & $\begin{array}{c}\text { Sensitivity } \\
(1 \mathrm{kHz}) \\
{[\mathrm{dB} / \mathrm{mW}]}\end{array}$ & $\begin{array}{c}\text { Weight } \\
{[\mathrm{g}]}\end{array}$ & $\begin{array}{c}\text { Passive } \\
\text { reduction } \\
{[\mathrm{dB}]}\end{array}$ & $\begin{array}{c}\text { Cost } \\
{[\mathrm{USD}]}\end{array}$ \\
\hline Creative Zen Aurvana & 42 & $20-20000$ & 115 & 13 & - & 104 \\
\hline Sony MDR-NC022 & 8.5 & $8-22000$ & 100 & - & - & 50 \\
\hline Sennheiser IE8 & 16 & $10-20000$ & 125 & 15 & 26 & 400 \\
\hline
\end{tabular}

\section{Experiments}

For experiments, three active earplugs have been tightly sealed to the ear canal of a G.R.A.S. artificial head via an adaptor representing the human outer ear (Figs. 3b, 4b, 5b). The sampling frequency has been chosen as $24 \mathrm{kHz}$. Frequency responses of the secondary and primary paths for every earplug are presented in Fig. 6. Real-world noise recorded in the Power Plant in Rybnik, Poland, has been used. Its PSD is presented in Fig. 7 by the dotted red line. The Wiener filter has been designed for every earplug separately, based on the generalised disturbance of a Gaussian PSD. The PSD covers the frequencies of 100-700 Hz, representing dominating components of the primary noise.

The results obtained are presented in Table 2 and Figs. 7-12. It is observed that passive noise reduction for the Creative earplug is better than for the Sony earplug, but much worse than for the Sennheiser earplug. The best total noise reduction is obtained using the Sennheiser earplug, mostly due to its impressive 
a)
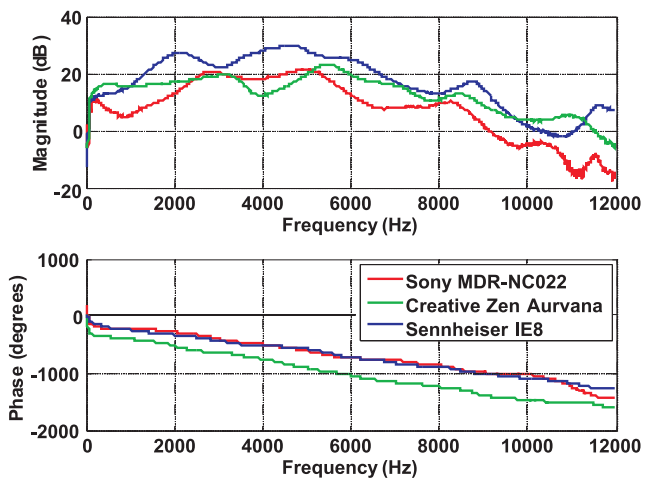

b)
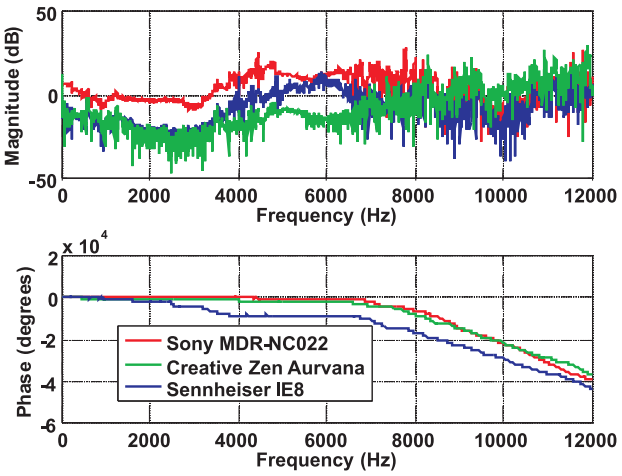

Fig. 6. Frequency responses of the secondary path (a) and primary path (b) for different earplugs.

a)

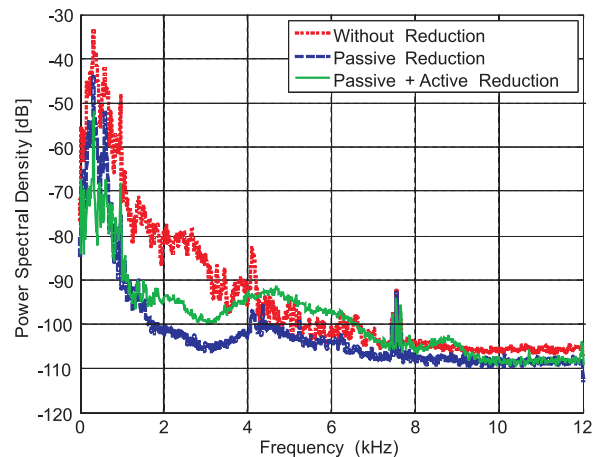

b)

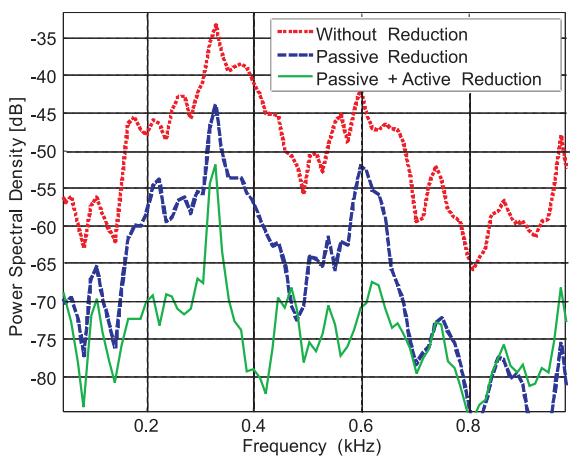

Fig. 7. Frequency domain control results for the Creative Zen Aurvana earplug.

Table 2. Noise reduction levels.

\begin{tabular}{|l|c|c|c|c|}
\hline Earplug actuator & $\begin{array}{c}\text { Active } \\
\text { Reduction } \\
\text { for the } \\
\text { frequency } \\
\text { band } \\
100-700 \mathrm{~Hz} \\
{[\mathrm{~dB}]}\end{array}$ & $\begin{array}{c}\text { Total } \\
\text { Reduction } \\
\text { for the } \\
\text { frequency } \\
\text { band } 100-700 \mathrm{~Hz} \\
{[\mathrm{~dB}]}\end{array}$ & $\begin{array}{c}\text { Active } \\
\text { Reduction } \\
\text { for all } \\
\text { frequencies } \\
{[\mathrm{dB}]}\end{array}$ & $\begin{array}{c}\text { Total } \\
\text { Reduction } \\
\text { for all } \\
\text { frequencies } \\
{[\mathrm{dB}]}\end{array}$ \\
\hline Creative Zen Aurvana & 10.2 & 22.6 & 9.9 & 22.4 \\
\hline Sony MDR-NC022 & 18.4 & 22.9 & 15.3 & 19.9 \\
\hline Sennheiser IE8 & 11.2 & 35.2 & 9.4 & 33.3 \\
\hline
\end{tabular}




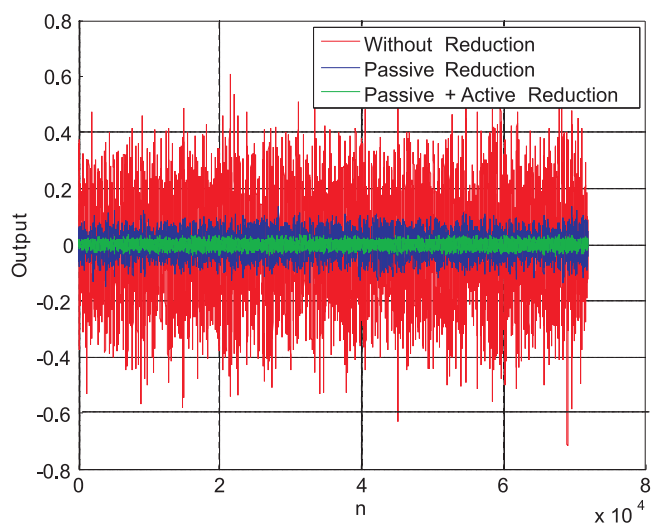

Fig. 8. Time domain control results for the Creative Zen Aurvana earplug.

a)

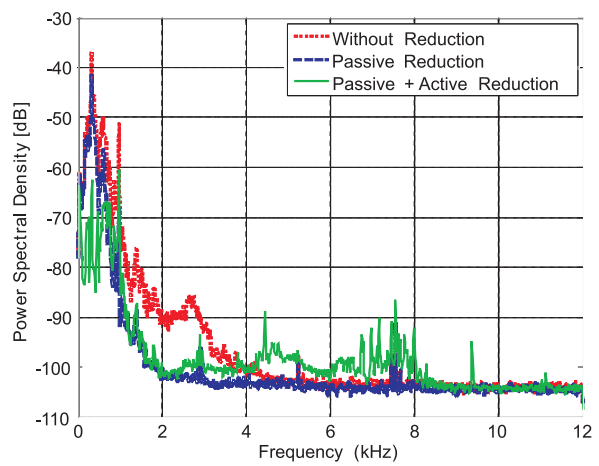

b)

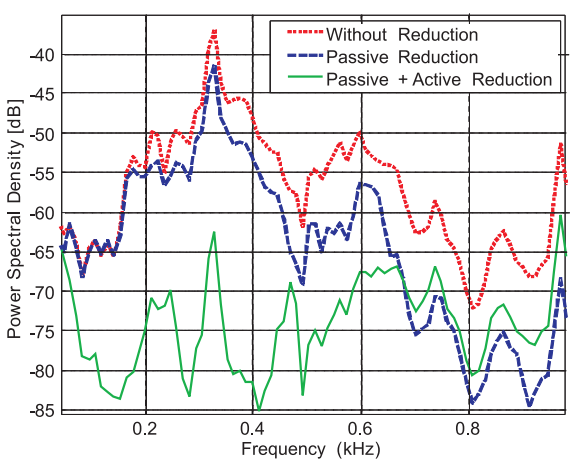

Fig. 9. Frequency domain control results for the Sony MDR-NC022 earplug.

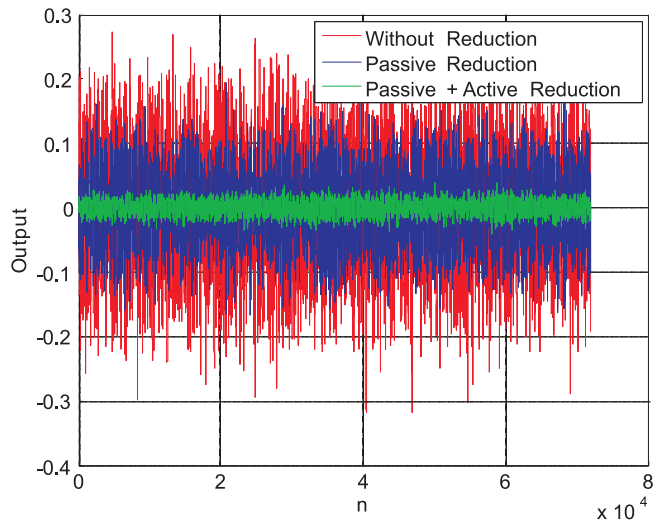

Fig. 10. Time domain control results for the Sony MDR-NC022 earplug. 
a)

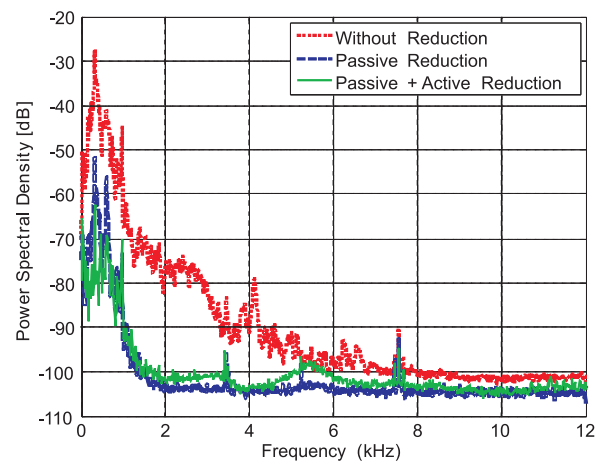

b)

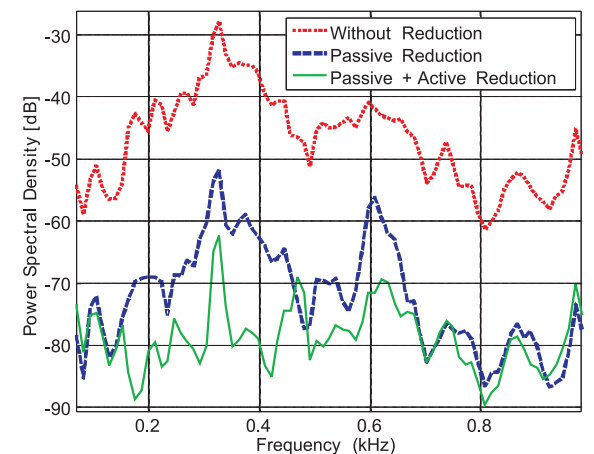

Fig. 11. Frequency domain control results for the Sennheiser IE8 earplug.

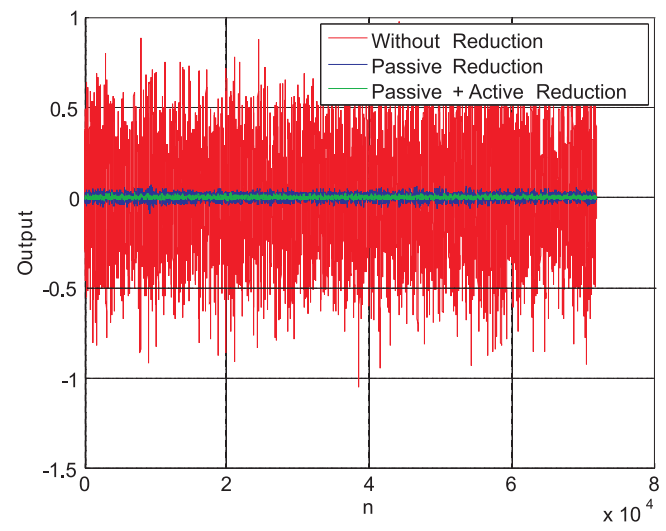

Fig. 12. Time domain control results for the Sennheiser IE8 earplug.

passive reduction, which is rather rare for such a miniature active device. However, the cost of this earplug is about four times higher than the cost of the other earplugs under consideration. The Sony earplug allows to obtain the highest active reduction. In general, total noise reduction obtained for the Sony and Creative earplugs are similar, and their cost is comparable. However, the advantage of the Sony earplug is that it has a built-in microphone. For the Sennheiser and Creative earplugs, small-size microphones should be added.

\section{Conclusions}

In this paper, fixed-parameter active control of sound in the feedforward structure for different types of earplugs has been considered. Referring to practical applications where the noise to be reduced is non-stationary and the plant changes 
little, the idea of the generalised disturbance has been used for the Wiener filter design procedure. Despite the relatively low passive reduction level obtained using the Sony MDR-NC022 earplug, it seems to be a good compromise to take into consideration other practical aspects.

\section{Acknowledgment}

The research reported in this paper has been partially supported by the Ministry of Higher Education and Science, Poland, under the grant no. N N514 232037 in 2010 .

\section{References}

1. Bockstael A., De Greve B. (2008), Verifying the attenuation of earplugs in situ: Method validation using artificial head and numerical simulations, Journal of the Acoustical Society of America, 124, 2, 973-981.

2. Elliott S.J. (2001), Signal Processing for Active Control, Academic Press, London.

3. Elliott S.J. (2009), Active Control in Vehicles and in the Inner Ear: a Review, International Journal of Acoustics and Vibration, 14, 4, 212-219.

4. Engel Z. (1984), Active Reduction of Vibration and Noise [in Polish: Aktywna redukcja drgan $i$ hatasu], Proceedings of the 11th Conference on Vibration in Physical Systems, Poznań, Poland.

5. Engel Z., Kowal J. (1995), Control of Vibroacoustic Processes [in Polish: Sterowanie Procesami Wibroakustycznymi], University of Mining and Metalurgy Press, Kraków.

6. Engel Z., Makarewicz G. (2001), Active Noise and Vibration Reduction Methods [in Polish: Metody Aktywne Redukcji Hałasu], CIOP Press, Warszawa.

7. Larsson M., Johansson S., Claesson I., Hakansson L. (2009), A Module Based Active Noise Control System for Ventilation Systems, Part I: Influence of Measurement Noise on the Performance and Convergence of the Filtered-x LMS Algorithm, International Journal of Acoustics and Vibration, 14, 4, 188-195.

8. Latos M., PaweŁczyk M. (2009a), Feedforward fixed-parameter control of non-stationary noise, Proceedings of the 56th Open Seminar on Acoustics - OSA56, Goniadz, Poland.

9. Latos M., PaweŁczyk M. (2009b), Feedforward vs Feedback Fixed-Parameter $\mathrm{H}_{2}$ Control of Non-Stationary Noise, Archives of Acoustics, 34, 4, 407-421.

10. Latos M., PaweŁczyk M. (2009c), Fixed-parameter control of non-stationary acoustic noise, Proceedings of the 16th International Congress on Sound and Vibration - ICSV16, Kraków, Poland.

11. Nelson P., Elliott S. (1992), Active Control of Sound, Academic Press Ltd.

12. PaweŁczyk M. (1999), Active Noise Control for Compact Acoustic Plants, J. Skalmierski Computer Studio, Gliwice. 
13. Paweeczyk M. (2005), Feedback Control of Acoustic Noise at Desired Locations, Silesian University of Technology, Gliwice.

14. Pawelczyk M. (2009), Analog Active Control of Acoustic Noise at a Virtual Location, IEEE Transactions on Control Systems Technology, 17, 2, 465-472.

15. Saxena G., Ganesan S., Das M. (2008), Real-time Implementation of Adaptive Noise Cancellation, IEEE International Conference on Electro/Information Technology, 431-436.

16. Vidyasagar S. (1985), Control Systems Synthesis. A Factorization Approach, MIT Press, Cambridge.

17. Widrow B., Stearns S.D. (1985), Adaptive Signal Processing, Prentice Hall, New Jersey.

18. Williams W. (2008), Hearing protector testing and individual variability, Acoustics Australia, 36, 2, 60-62. 